\title{
POSSIBILITIES FOR APPLICATION OF E-CMR FROM A CUSTOMS POINT OF VIEW
}

\author{
Momchil Antov, PhD \\ Faculty of Economic Accounting, D. A. Tsenov Academy of Economics - Svishtov, Bulgaria \\ m.antov@uni-svishtov.bg
}

\begin{abstract}
Given the widespread development of information technology in business and government, it is increasingly logical to introduce electronic documents that partially or completely replace paper ones. In the EU Member States, the digitalisation of customs controls is at one of the best levels in the world, but there are still areas where paperwork is the only way to process specific information on cross-border trade in goods. As such an area, the information in the transport documents for the carriage of goods by road, known as CMR waybills, may be indicated. In this report, we will try to look at the trends in Europe regarding the application of electronic CMR (e-CMR) and the importance of this process for the customs control system. The information on each transport operation is of great importance to the customs and is a key component of their risk analysis to detect illegal cross-border movements of goods. By its nature, the movement of goods is a risk area because the possibilities for control by the customs authorities are very limited. Therefore, opportunities should be sought here for the introduction of effective measures to ensure the proper application of customs control functions. The linking of information from electronic consignment notes to customs information systems can be seen as a measure that would significantly contribute to the overall digitalisation of customs control.
\end{abstract}

Keywords: Customs control, Customs digitalization, Electronic consignment note

JEL classification: M49

\section{INTRODUCTION}

Among the numerous conventions that regulate relations in the field of transport, the Convention on the Contract for the International Carriage of Goods by Road (CMR Convention) of 19 May 1956, concluded under the auspices of the United Nations Economic Commission for Europe (United Nations, 1956), occupies an important place. The consignment note by its nature is not a commodity-disposal document, but serves as proof of accurate and timely delivery of goods to the final destination (Mladenov, 2000, p. 188). It can also be defined as a tripartite contract, the parties to which are the consignor, carrier and consignee of the goods. From a customs point of view, the consignment note is an important source of information on individual parameters of the transport operation, which are also important for the proper conduct of customs formalities. In practice, it is a proof of transport of the goods described in it and imposes certain responsibilities on the persons specified in it. Due to this role, it is not possible to admit goods in the customs processes without the presence of a consignment note according to the type of transport used.

Some forecasts show that the volume of road freight is expected to increase by more than $50 \%$ by 2050 (European Commission, 2016, p. 2). This means that paperwork will become an even more serious problem in the coming years, and CMR paper consignment notes are invariably present in it. The European Parliament and the Commission have repeatedly called for a stronger commitment to paperless transport in the EU and called for a simpler, fully electronic, continuous, transparent, secure and reliable flow of information between economic operators and control bodies covering cross-border goods traffic. In terms of the processes developing everywhere for automation of many activities, incl. and in transport, logistics and forwarding, 
it is necessary, where possible, to make electronic document exchange mandatory. The risk of the COVID-19 virus spreading through the exchange of paper documents between those employed in these sectors and the relevant control authorities must now be taken into account. At the same time, it is necessary to take the appropriate steps on the part of the state administration for the acceptance and recognition of such electronic documents (consignment notes), incl. and electronic copies of already issued ones on paper.

\section{SCOPE OF THE e-CMR PROTOCOL}

In modern dynamic conditions, the time for delivery of goods is considered as one of the most important factors related to the efficiency of transport systems. New means and mechanisms for its reduction are constantly being sought, while at the same time efforts are being made to increase the quality of transport services and the added value in the sector. Achieving these goals is possible through the automation of some processes and their transfer to an electronic environment. The digitalisation of cross-border road transport is encouraging the process of moving from a paper to an electronic version of the CMR consignment note, with more and more countries joining this initiative. This could save transport companies a lot of costs and make them more efficient and sustainable. It should be borne in mind, however, that this does not mean an obligation for participants in transport operations (consignors, carriers and consignees) to use only electronic transport documents, but an opportunity to optimize their activities.

\subsection{Application of the e-CMR Protocol}

The rules for the carriage of goods by road internationally are covered by the CMR Convention, which has been ratified by most European countries, as well as by several other countries around the world. Freight companies, consignors and consignees use the CMR consignment note, which contains information on the goods loaded, the persons involved in the transport operation and the places for loading and receiving the goods. Until recently, CMR consignment note took place only on paper and against the background of the universal digitalisation of logistics and transport, business stakeholders and governments are pushing for a transition to an electronic format for this document. Of fundamental importance in this regard is the Additional Protocol to the Convention on the contract for the international carriage of goods by road (CMR) concerning the electronic consignment note (United Nations, 2008). This Protocol entered into force on 5 June 2011 and has currently been ratified by 27 States (see Table 1), representing about half of the 56 Member States of the CMR Convention. However, it should be borne in mind that only 6 of these countries (Spain, France, Estonia, Finland, the Netherlands and Luxembourg) actually carry out the electronic version of the CMR consignment note, which shows a rather limited geographical scope and a relatively small volume of cargo. According to the European Commission for 2017, road transport accounts for 50\% of the total freight transport in the EU, as the 6 countries implementing e-CMR have realized about $30 \%$ of this traffic (European Commission, 2020, p. 36). However, the available data do not show the share of e-consignment notes and the share of paper waybills, which does not allow more accurate conclusions to be drawn about the importance of e-CMR for the EU transport sector.

Given the implementation of the European Commission's Mobility Package 3, which introduces a regulation guaranteeing that all state institutions in the EU Member States should receive data in electronic format, it can be said that the full introduction and use of electronic transport documents in the EU is only a matter of time. On 7 April 2020, the Council of the European Union approved the report on information on electronic freight transport (eFTI), adopted by the European Parliament's Transport Committee in January of that year. On 8 July 2020, the European Parliament adopted in its plenary meeting the Regulation on electronic Freight Transport Information (eFTI) (Regulation (EU) 2020/1056 of the European parliament and of the Council of 15 July 2020 on electronic freight transport information, 2020). The regulation 
obliges all competent public authorities to accept electronic information through certified platforms (by 2025 at the latest) if companies wish to provide data in this way to demonstrate compliance with legal requirements. All this shows that the digital exchange of information from road consignment notes in Europe between actors in supply chains, customs administrations and other stakeholders is entirely possible. However, account should be taken of the fact that eFTI information is currently envisaged to be summarized at Brussels level and not in the individual EU Member States. In practice, information on individual shipments will be collected at the level of an individual Member State (consignor or consignee) and then directed to a common platform to which other EU Member States covered by the transport have access.

Table 1: States that have ratified the Additional Protocol to the CMR Convention

\begin{tabular}{|c|c|c|c|}
\hline Participant & Signature & Ratification & Accession \\
\hline Belarus & & & 7 Feb 2019 \\
\hline Belgium $^{1}$ & 27 May 2008 & & \\
\hline Bulgaria & & & 15 Sep 2010 \\
\hline Czech Republic & & & 14 Apr 2011 \\
\hline Denmark & & & 28 Jun 2013 \\
\hline Estonia & & & 2 Nov 2016 \\
\hline Finland & 27 May 2008 & 11 Jan 2019 & \\
\hline France & & & 5 Oct 2016 \\
\hline Iran (Islamic Republic of) & & & 8 Nov 2017 \\
\hline Latvia & 27 May 2008 & 3 Feb 2010 & \\
\hline Lithuania & 27 May 2008 & 7 Mar 2011 & \\
\hline Luxembourg & & & 26 Dec 2017 \\
\hline Netherlands & 28 May 2008 & 7 Jan 2009 & \\
\hline Norway & 27 May 2008 & & 17 Jun 2020 \\
\hline Poland & & & 13 Jun 2019 \\
\hline Portugal & & & 26 Sep 2019 \\
\hline Republic of Moldova & & & 14 Mar 2018 \\
\hline Romania & & & 14 Mar 2019 \\
\hline Russian Federation & & & 6 Mar 2018 \\
\hline Slovakia & & & $21 \mathrm{Feb} 2014$ \\
\hline Slovenia & & & 15 Aug 2017 \\
\hline Spain & & & 11 May 2011 \\
\hline Sweden & 27 May 2008 & 9 Mar 2020 & \\
\hline Switzerland & 27 May 2008 & 26 Jan 2009 & \\
\hline Tajikistan & & & 9 Jul 2019 \\
\hline Turkey & & & 31 Jan 2018 \\
\hline Ukraine & & & $10 \mathrm{Jul} 2020$ \\
\hline $\begin{array}{l}\text { United Kingdom of Great Britain } \\
\text { and Northern Ireland }\end{array}$ & & & 20 Dec 2019 \\
\hline
\end{tabular}

(Source: https://treaties.un.org/pages/ViewDetails.aspx?src=TREATY\&mtdsg_no=XI-B-11$\underline{b \& \text { chapter }=11 \& \text { clang }=\text { en, last visit: } 28.09 .2020)}$

For its part, the effective implementation of the e-CMR e-consignment note was launched in January 2017, when the first such transport of goods between Spain and France took place. As

\footnotetext{
${ }^{1}$ Belgium signed the e-protocol on 27 May 2008 but has not ratified it to this day.
} 
mentioned above, from the geographical distribution of e-CMR shipments, it can be concluded that they are not yet widespread. The reason for this can be found both in the still small number of countries that have ratified the e-CMR Protocol and in the need to build the relevant electronic platforms. The reason for the slow entry of electronic transport documents can be pointed out the lack of universal recognition of the legal equivalence of electronic documents by the competent state authorities. It is also influenced by the fragmented IT environment, in which in many places there are no established and interoperable systems with generally applicable and binding rules on electronic data interchange. Practical difficulties in using eCMR also arise where the point of loading and the point of delivery of the goods are not in neighbouring countries, but require the consignment to be transported through countries that do not accept e-CMR. All this shows that maximizing the benefits of electronic documents requires the participation of more countries and the development of single electronic e-CMR platforms accessible to all stakeholders in those countries. The introduction of eFTI will certainly intensify these processes and will be a major reason for achieving a wider digitalisation of freight transport in the EU Member States.

\subsection{Features of the e-CMR electronic consignment note}

According to the Additional Protocol to the CMR Convention, the electronic consignment note has the same probative value and functions provided that it contains all the mandatory details and is the full equivalent of the paper consignment note. The Protocol also clearly mentions the requirements that the e-CMR electronic consignment note must meet to have legal force and practical application, and these are:

$>$ To have a unique number;

$>$ To be signed with an electronic signature;

$>$ To apply special technology for its use (according to art. 1-6 of the Protocol):

- contain the same information as the paper consignment note;

- the e-consignment note is created by a registered and eligible for state administration software provider;

- the software provider must provide information to the competent authorities, the consignor, the freight forwarder acting as a commission agent;

- the software provider must maintain a database, a list of all e-consignment notes issued by it and provide them to the competent authorities if necessary;

- the parties to the transport operation to accept the e-consignment notes as a valid alternative to the paper one, if it meets the requirements of Art. 1-6 of the Protocol.

The introduction of electronic consignment notes aims to reduce administrative costs and the time required to process the information contained in them, and these benefits can be identified both for business and for the various control authorities. The objectives fulfilled by the consignment note are not only preserved in its electronic version, but also new possibilities are added in terms of both the security of the data and their type and volume. Most e-CMR platforms allow the attachment of photos to waybills from the moment the goods are loaded or unloaded, which is very useful in identifying possible problems with their quantity, type and condition.

For e-CMR platforms to work well, it is necessary to have opportunities for standardized data exchange not only between the economic operators using them, but also between the platforms themselves. This is necessary due to the possibility of individual participants in the transport operation to use different platforms. For example, there are currently 11 accredited e-CMR providers in the Benelux region alone. They all meet the requirements of the e-CMR protocol, but without the exchange of certain data between them, the effect of their use would be controversial. 


\section{APPLICATION OF E-CMR IN CUSTOMS CONTROL}

The e-CMR e-consignment note project can enable businesses and control bodies to optimize the processes of import, export or transit of goods by integrating their activities into common networks of information systems. This will not only increase the speed of information exchange between all stakeholders in the supply chain but could also minimize errors and prevent fraud. At the same time, control authorities could increase their efficiency by focusing on other aspects of transport operations and identifying possible disturbances in cross-border traffic of goods by road on time. On the other hand, the application of standardized electronic communications in freight transport can facilitate further interaction of stakeholders with other modes of transport and with other national public administrations (United nations center for trade facilitation and electronic business (UN/CEFACT), 2018, p. 6) (tax administration, veterinary control, phytosanitary control, market surveillance authorities, etc.).

According to the CMR Convention, a road consignment note affects private legal relations between the parties to a contract of carriage in the context of international road transport and in this sense has no significant consequences for public authorities. However, the consignment note is used by many government institutions to control shipments, and for customs authorities it plays a leading role in trade with EU third countries. About to the use of e-CMR instead of a paper consignment note, there is a problem as to the extent to which the customs authorities can accept monitoring carried out on the screen of a mobile device or on a paper printout available in the vehicle. In practice, the question arises as to whether the customs authorities can have sufficient confidence in the electronic consignment note. The answer to this question may have to be sought in who administers the online e-CMR publishing platforms - a private organization, the state or a joint venture. Currently, the existing e-CMR platforms on the territory of the EU member states, which also apply this version of the consignment note, have been developed and sold as a private initiative. However, no problems have yet been identified and reported by the customs authorities regarding the security and reliability of the data exchanged on cargo between those involved in transport operations, which can be considered as a quality certificate for this electronic document.

The eFTI Regulation introduces the use of new platforms for the provision of transport information, and e-CMR is not specifically covered by it. However, it should be borne in mind that in practice there is a significant overlap of information on both types of platforms. This information refers to data on the persons involved in the transport operations, the type, packaging and quantity of the transported goods, the place of loading and unloading, etc. This data contained in the e-CMR overlaps with the information required by the customs authorities to prove compliance with customs formalities for goods transported across borders by road. Directly speaking, e-CMR can play an important role as proof of compliance and even lead to a reduction in the volume of data submitted by economic operators to customs authorities. This information may be used both in the framework of the preliminary control and risk analysis carried out through submitted Entry summary declarations or Exit summary declarations, and at the end of customs procedures for customs clearance of goods. The use of electronic transport documents can be considered as a precondition for granting new customs simplifications, based on the information contained in them to automate (in whole or in part) the processing of certain customs documents, such as entry or exit summary declaration, temporary storage declaration, re-export notification, etc.). From a legal point of view, this is legally regulated because customs legislation in the EU (Union Customs Code - UCC) (Regulation (EU) No 952/2013 of the European Parliament and of the Council of 9 October 2013 laying down the Union Customs Code, 2013) provides for possibilities to use "electronic transport documents" instead of customs declarations (CLECAT Digitalisation WG, 2020, p. 31). Such an approach is partly supported by the introduction through eFTI of a requirement that when public authorities can retrieve information electronically, they should not require its retransmission by economic 
operators. However, the fact that the customs must use a specific system for coding goods (Harmonized Systems code), which is not mandatory for use in transport documents, must also be considered here. The introduction of a requirement to indicate the HS-code of goods in these documents may make it difficult for economic operators or lead to significant inaccuracies.

Member State authorities will have various requirements regarding a solution for sharing (access to) data of eTransport Documents. First, the solution has to fit a particular inspection regime and secondly it has to provide a guaranteed data quality. There are also particular archiving laws to consider in this respect. Administrative burden should not increase, which means that the once-only principle has to be obeyed (European Commission, 2018). The eCMR concept imposes some requirements on stakeholders using this consignment note option:

\section{$>$ Requirements for customs authorities:}

- to accept electronic information for forthcoming or realized transport, provided by the economic operators;

- apply harmonized rules for access to electronic information;

- to use a common set of data for electronic information processing.

\section{Requirements to economic operators:}

- the information should be provided to the authorities through certified e-CMR platforms:

- in machine-readable format;

- in a human-readable format, if (explicitly) requested by the relevant authority.

\section{Requirements for e-CMR platforms and e-CMR service providers:}

- e-CMR platforms must meet certain functional requirements to ensure, among other conditions, the authenticity, integrity and cybersecurity of the data;

- providers of such services must keep the data for a certain period of time, provide access to them to the competent authorities, etc.

Many documents that are sent with the goods have a similar content of the consignment note (packing lists, proofs of origin, specifications, etc.), which can and should lead to optimization of commercial and transport documents, incl. and from a customs point of view. These documents contain several repetitive data, such as who sends the goods, to whom they send them, what they send (type, quantity, value), what type of transport is carried out, etc. In practice, there is a circulation of the same information in different systems, without many possibilities for its reuse. At the same time, there are many standards developed for document management, incl. and for the electronic exchange of specific information that is not fully used. A number of standards are widely used in customs - WCO Data model, developed by UN / CEFACT standard EDIFACT (messaging widely adopted and implemented in logistics), Multi Modal Transport model (MMT), Transport Data Model (EUTDM), as well as some other specific modules for transport by sea or rail. Creating opportunities for the exchange of information between the various transport and customs systems following these standards would make a significant contribution to achieving a better electronic environment in the sector and maximizing the benefits of the use of electronic documents.

\subsection{Application of e-CMR in the import of goods}

The implementation of each import operation is associated with the submission and execution of several documents, the consignment note is one of those mandatory. It accompanies the goods during transport, and in the country of importation before customs clearance of the goods it is not permissible to make any additions or corrections in it (except in cases of objective circumstances during the transport of the goods, affected their quantity and quality). This allows the customs authorities to consider the information in the consignment note as a basis for checking the actual condition of the imported goods in terms of type and quantity. The use of the possibility for the customs authorities to access the data for a specific transport with e-CMR is a prerequisite for the timely establishment of possible discrepancies regarding the type and 
quantity of the declared goods and those actually located in the cargo space of the vehicle. At the same time, e-CMR can also be considered as reliable proof of receipt and delivery of goods in the case of import under the simplified procedure " Entry in the declarant's records" (Article 182 of the UCC). In this case, the importer is released from the obligation to present the goods to the customs authorities and they carry out a risk analysis to carry out a possible verification only based on the information submitted to them.

The information from e-CMR may also serve other customs formalities when importing goods, as similar possibilities are provided for the submission of the Entry summary declaration (Article 127, paragraph 7 of the UCC) and the Temporary storage declaration (Article 145, paragraph 6 of the UCC). The customs authorities may accept that commercial, port or transport information systems are used to lodge a Temporary storage declaration provided that they contain the necessary particulars for such declaration. The customs authorities may also accept that the Temporary storage declaration is made in the form of a transport document, provided that it contains the particulars of a Temporary storage declaration, including a reference to any entry summary declaration for the goods concerned (Article 145, paragraph 5 of the UCC).

The above examples show that CMR e-consignment notes can have important applications in import customs procedures, with the benefits of their application for both economic operators and customs authorities. The information contained therein can successfully power the relevant modules of the customs information systems and allow effective controls to be carried out on imported goods so that the functions and tasks of customs control are fully achieved.

\subsection{Application of e-CMR in the export of goods}

Like the documentation of imports of goods, consignment notes play an essential role in export customs formalities. They prove the conclusion of a contract for the transport of the goods declared for export to a place outside the customs territory of the EU. Based on the information contained therein, the customs authorities may seek equality between the goods declared and prepared for export. The use of e-CMR also provides additional post-release controls options, as the customs authorities could check in the system what type and quantity of goods are accepted by their final consignee in the third country. This means that e-CMR could be considered as proper proof of completed exports, even in cases where there are not regularly completed SADs or Exit summary declarations.

The Union Customs Code provides some opportunities to streamline export procedures by allowing customs authorities to accept the use of commercial, port or transport information systems to submit an Exit summary declaration (Article 271, paragraph 3 of the UCC) or notification of re-export (Article 274, paragraph 3 of the UCC), provided that they contain the necessary particulars for such notification and these particulars are available before the goods are taken out of the customs territory of the Union. In practice, this means that the use of eCMR can contribute to the simplification of export customs procedures by releasing economic operators from the obligation to submit the same data several times to different control systems. The introduction of electronic consignment notes would also have a direct effect on the VAT administration processes, both on the part of businesses and the part of the competent national control authorities. Paper document circulation in transport processes is associated with the presence of many difficulties, primarily related to the delay of the relevant documents in time, and often due to their loss. This leads to some problems in proving to the tax authorities the international transport of goods in the direction of their export and the provision of services for the transport processing of exported goods. The impossibility of proving such carriage deprives exporters of the right to a timely refund of VAT paid on the goods exported by them, which has a direct financial and economic effect on their business. Overcoming these problems is entirely possible using of e-CMR in export operations and the addition of electronic consignment notes to documents proving international transport. At present, however, not all EU Member States 
have updated their tax legislation in this direction and the proof of international transport and transport handling services cannot be done with the electronic equivalent of a CMR consignment note. With the introduction of eFTI, this will soon change and then e-CMR will become the preferred option for documenting international road haulage, at least by legally operating economic operators.

\subsection{Application of e-CMR in the transit of goods}

Transit, by its very nature, allows the transport of goods from one place to another in a customs territory, and they are placed under customs supervision during its course. The Transit regime is ancillary to other customs regimes, but it is part of the logical development of customs control from a spatial point of view. It can precede the application of one regime or finalize the development of another, ie. transit cannot be considered as a separate process. However, its proper organization and implementation is a challenge for both economic operators and customs.

From the point of view of the customs processing of consignment notes for goods under the Transit procedure, it is important in the first place to take into account where the consignor of the goods is positioned - at the office of departure or destination. This is important from a customs point of view because in the first case the transport will start and the consignment note will show the type and quantity of goods sent, and in the second case the transport will end and the consignment note will prove the type and quantity of goods received. In both cases, e-CMR can ensure that real-time access to this data is available and that the customs authorities take it into account when initiating or terminating the transit operation. Such a possibility is provided in the European customs legislation, as according to art. 233 (4) (e) of the UCC, the customs authorities may authorize certain simplifications of customs procedures with regard to the placing of goods under the Union transit procedure or the termination of that procedure. In practice, the use of an electronic transport document as a customs declaration for placing goods under the Union transit procedure is permitted, provided it contains the particulars of such declaration and those particulars are available to the customs authorities at departure and at destination to allow the customs supervision of the goods and the discharge of the procedure. It is essential for the transit of goods under customs supervision to link e-CMR to eTIR. Almost all customs administrations use IT systems, including the TIR Customs Portal, to manage their procedures and exchange information in real-time with fellow national agencies, with trade actors or with international partners (customs or organizations such as UNECE or IRU). TIR Electronic Pre-Declarations (TIR-EPD), developed by IRU, enable TIR operators to send advance cargo information and exchange messages with multiple customs authorities throughout a TIR transport, in full respect of all national customs requirements and the format of information to be submitted. This application is used widely by transport operators and their representatives. It saves border waiting time and reduces transport operator costs, while allowing customs to do proper risk assessment (IRU, 2020). The exchange of information between e-CMR and eTIR systems will significantly intensify the processing of transit operations through the EU Member States and would have a positive effect on all stakeholders.

\section{CONCLUSION}

The ongoing processes of digitalization of our society have an impact on the transport sector, and the tendency to move to the processing of related documents in an electronic environment is becoming increasingly important. The gradual development and implementation of electronic consignment notes are one of the main steps that must be taken to achieve the desired effect of these processes. Customs controls in EU member states also use IT and more and more procedures are covered by electronic documents. In this regard, the exchange of information between transport systems and customs systems should be seen as a logical continuation of efforts to build an e-society and e-government. 
Due to its digital nature, e-CMR can be easily integrated with many services used by transport companies, such as customs clearance or freight forwarding management services. Also, the information from e-CMR can be electronically received in several other external systems, such as customs and to service the processes developed in them. In practice, e-CMR information can be used as a reliable signal to start certain processes or as evidence of their completion. In this way, the effect of the use of electronic waybills could be multiplied and their application would have a positive effect on all participants in transport operations. The main purpose of the use of electronic documents (not only in transport) is to create opportunities for the exchange of information contained in them, not just their existence. It is, therefore, necessary to make eCMR platforms operating in different countries interoperable (single format for data exchange or use of a common interface). This would allow an e-CMR created on the platform of one provider of a similar service to be signed by a user on the platforms of other providers. This example shows that to increase the usefulness of the use of e-CMR, it is necessary not only to expand the geographical scope of the countries using it but also to unify the type of information collected in electronic platforms so that it can be shared with all stakeholders. Then the customs could expand the scope of application of information from e-CMR and improve the automation of several of its processes.

\section{REFERENCES}

CLECAT Digitalisation WG, 2020. The eFTI Regulation \& the DTLF. Brussels: CLECAT. European Commission (2016), Combined Transport Directive 92/106/EEC, Final Report, European Commission, Brussels.

European Commission (2018), Towards paperless transport within the EU and across its borders - Report, European Commission, Brussels.

European Commission (2020), EU transport in figures - Statistical pocketbook 2019. European Commission, Brussels.

IRU, $2020 . \quad$ The future of TIR is digital, available at: https://www.iru.org/what-we-do/facilitating-trade-and-transit/tir/future-tir-digital (accessed 10 June 2020).

Mladenov, P. (2000), Customs representation and agency, Ciela, Sofia.

Regulation (EU) 2020/1056 of the European parliament and of the Council of 15 July 2020 on electronic freight transport information (2020).

Regulation (EU) No 952/2013 of the European Parliament and of the Council of 9 October 2013 laying down the Union Customs Code (2013).

United nations center for trade facilitation and electronic business (UN/CEFACT) (2018), Business requirements specification (BRS) e-CMR, United nations economic commission for Europe, Geneva.

United Nations (1956), Conventionon the contract for the international carriage of goods by road ( $C M R$ ), United Nations, Geneva.

United Nations (2008), Additional Protocol to the Convention on the contract for the international carriage of goods by road (CMR), United Nations, Geneva. 